\title{
Best proximity points and extension of Mizoguchi-Takahashi's fixed point theorems
}

\author{
Poom Kumam ${ }^{1}$, Hassen Aydi ${ }^{2}$, Erdal Karapınar ${ }^{3}$ and Wutiphol Sintunavarat4 ${ }^{4 *}$
}

Dedicated to Prof. W Takahashi on the occasion of his 70th birthday

\author{
Correspondence: \\ poom_teun@hotmail.com; \\ wutiphol@mathstat.sci.tu.ac.th \\ ${ }^{4}$ Department of Mathematics and \\ Statistics, Faculty of Science and \\ Technology, Thammasat University \\ Rangsit Center, Pathumthani, 12121, \\ Thailand \\ Full list of author information is \\ available at the end of the article
}

\begin{abstract}
In this paper, we introduce a multi-valued cyclic generalized contraction by extending the Mizoguchi and Takahashi's contraction for non-self mappings. We also establish a best proximity point for such type contraction mappings in the context of metric spaces. Later, we characterize this result to investigate the existence of best proximity point theorems in uniformly convex Banach spaces. We state some illustrative examples to support our main theorems. Our results extend, improve and enrich some celebrated results in the literature, such as Nadler's fixed point theorem, Mizoguchi and Takahashi's fixed point theorem.
\end{abstract}

MSC: 41A65; 46B20; 47H09; 47H10

Keywords: best proximity points; multi-valued contraction; cyclic contraction; $\mathcal{M T}$-function (or $\mathcal{R}$-function)

\section{Introduction}

It is evident that the fixed point theory is one of the fundamental tools in nonlinear functional analysis. The celebrated Banach contraction mapping principle [1] is the most known and crucial result in fixed point theory. It says that each contraction in a complete metric space has a unique fixed point. This theorem not only guarantees the existence and uniqueness of the fixed point but also shows how to evaluate this point. By virtue of this fact, the Banach contraction mapping principle has been generalized in many ways over the years (see e.g., [2-5]).

Investigation of the existence and uniqueness of a fixed point of non-self mappings is one of the interesting subjects in fixed point theory. In fact, given nonempty closed subsets $A$ and $B$ of a complete metric space $(X, d)$, a contraction non-self-mapping $T: A \rightarrow B$ does not necessarily yield a fixed point $T x=x$. In this case, it is very natural to investigate whether there is an element $x$ such that $d(x, T x)$ is minimum. A notion of best proximity point appears at this point. A point $x$ is called best proximity point of $T: A \rightarrow B$ if

$$
d(x, T x)=d(A, B)=\inf \{d(x, y): x \in A \text { and } y \in B\},
$$

where $(X, d)$ is a metric space, and $A, B$ are subsets of $X$. A best proximity point represents an optimal approximate solution to the equation $T x=x$ whenever a non-self-mapping $T$ has no fixed point. It is clear that a fixed point coincides with a best proximity point if $d(A, B)=0$. Since a best proximity point reduces to a fixed point if the underlying mapping 
is assumed to be self-mappings, the best proximity point theorems are natural generalizations of the Banach's contraction principle.

In 1969, Fan [6] introduced the notion of a best proximity and established a classical best approximation theorem. More precisely, if $T: A \rightarrow B$ is a continuous mapping, then there exists an element $x \in A$ such that $d(x, T x)=d(T x, A)$, where $A$ is a nonempty compact convex subset of a Hausdorff locally convex topological vector space $B$. Subsequently, many researchers have studied the best proximity point results in many ways (see in [7-14] and the references therein).

In the same year, Nadler [15] gave a useful lemma about Hausdorff metric. In paper [15], the author also characterized the celebrated Banach fixed point theorem in the context of multi-valued mappings.

Lemma 1.1 (Nadler [15]) If $A, B \in C B(X)$ and $a \in A$, then for each $\epsilon>0$, there exists $b \in B$ such that $d(a, b) \leq H(A, B)+\epsilon$.

Theorem 1.2 (Nadler [15]) Let $(X, d)$ be a complete metric space and $T: X \rightarrow C B(X)$. If there exists $r \in[0,1)$ such that

$$
H(T x, T y) \leq r d(x, y),
$$

for all $x, y \in X$, then $T$ has at least one fixed point, that is, there exists $z \in X$ such that $z \in T z$.

The theory of multi-valued mappings has applications in many areas such as in optimization problem, control theory, differential equations, economics and many branches in analysis. Due to this fact, a number of authors have focused on the topic and have published some interesting fixed point theorems in this frame (see [16-19] and references therein). Following this trend, in 1989, Mizoguchi and Takahashi [17] proved a generalization (Theorem 1.3 below) of Theorem 1.2; see Theorem 2 in Alesina et al. [20]. Theorem 2 is a partial answer of Problem 9 in Reich [21]. See also [22-24].

Theorem 1.3 (Mizoguchi and Takahashi [17]) Let $(X, d)$ be a complete metric space and $T: X \rightarrow C B(X)$. Assume that

$$
H(T x, T y) \leq \alpha(d(x, y)) d(x, y)
$$

for all $x, y \in X$, where $\alpha:[0, \infty) \rightarrow[0,1)$ is $\mathcal{M T}$-function (or $\mathcal{R}$-function), i.e.,

$$
\limsup _{x \rightarrow t^{+}} \alpha(x)<1
$$

for all $t \in[0, \infty)$. Then $T$ has at least one fixed point, that is, there exists $z \in X$ such that $z \in T z$.

Remark 1.4 In original statement of Mizoguchi and Takahashi [17], the domain $\alpha$ is $(0, \infty)$. However both are equivalent, because $d(x, y)=0$ implies that $H(T x, T y)=0$. 
Remark 1.5 We obtain that if $\alpha:[0, \infty) \rightarrow[0,1)$ is a nondecreasing function or a nonincreasing function, then $\alpha$ is a $\mathcal{M T}$-function. Therefore, the class of $\mathcal{M T}$-functions is a rich class, and so this class has been investigated heavily by many authors.

In 2007, Eldred et al. [25] claimed that Theorem 1.3 is equivalent to Theorem 1.2 in the following sense:

If a mapping $T: X \rightarrow C B(X)$ satisfies (1.2), then there exists a nonempty complete subset $M$ of $X$ satisfying the following:

(i) $M$ is $T$-invariant, that is, $T x \subseteq M$ for all $x \in M$,

(ii) $T$ satisfies (1.1) for all $x, y \in M$.

Very recently, Suzuki [26] gave an example which says that Mizoguchi-Takahashi's fixed point theorem for multi-valued mappings is a real generalization of Nadler's result. In his remarkable paper, Suzuki also gave a very simple proof of Mizoguchi-Takahashi's theorem.

On the other hand, Kirk-Srinavasan-Veeramani [27] introduced the concept of a cyclic contraction.

Let $A$ and $B$ be two nonempty subsets of a metric space $(X, d)$, and let $T: A \cup B \rightarrow A \cup B$ be a mapping. Then $T$ is called a cyclic map if $T(A) \subseteq B$ and $T(B) \subseteq A$. In addition, if $T$ is a contraction, then $T$ is called cyclic contraction.

The authors [27] give a characterization of Banach contraction mapping principle in complete metric spaces. After this initial paper, a number of papers has appeared on the topic in literature (see, e.g., [27-39]).

In this paper, we introduce the notion of a generalized multi-valued cyclic contraction pair, which is an extension of Mizoguchi-Takahashi's contraction mappings for non-self version and establish a best proximity point of such mappings in metric spaces via property UC* due to Sintunavarat and Kumam [40]. Further, by applying the main results, we investigate best proximity point theorems in a uniformly convex Banach space. We also give some illustrative examples, which support our main results. Our results generalize, improve and enrich some well-known results in literature.

\section{Preliminaries}

In this section, we recall some basic definitions and elementary results in literature. Throughout this paper, we denote by $\mathbb{N}$ the set of all positive integers, by $\mathbb{R}$ the set of all real numbers and by $\mathbb{R}_{+}$the set of all nonnegative real numbers. We denote by $C B(X)$ the class of all nonempty closed bounded subsets of a metric space $(X, d)$. The Hausdorff metric induced by $d$ on $C B(X)$ is given by

$$
H(A, B)=\max \left\{\sup _{a \in A} d(a, B), \sup _{b \in B} d(b, A)\right\}
$$

for every $A, B \in C B(X)$, where $d(a, B)=\inf \{d(a, b): b \in B\}$ is the distance from $a$ to $B \subseteq X$.

Remark 2.1 The following properties of the Hausdorff metric induced by $d$ are well known:

(i) $H$ is a metric on $C B(X)$.

(ii) If $A, B \in C B(X)$ and $q>1$ is given, then for every $a \in A$, there exists $b \in B$ such that $d(a, b) \leq q H(A, B)$. 
Definition 2.2 Let $A$ and $B$ be nonempty subsets of a metric space $(X, d)$ and let $T: A \rightarrow$ $2^{B}$ be a multi-valued mapping. A point $x \in A$ is said to be a best proximity point of a multivalued mapping $T$ if it satisfies the condition that

$$
d(x, T x)=d(A, B)
$$

We notice that a best proximity point reduces to a fixed point for a multi-valued mapping if the underlying mapping is a self-mapping.

A Banach space $X$ is said to be

(i) strictly convex if the following implication holds for all $x, y \in X$ :

$$
\|x\|=\|y\|=1 \quad \text { and } \quad x \neq y \quad \Longrightarrow \quad\left\|\frac{x+y}{2}\right\|<1
$$

(ii) uniformly convex if for each $\epsilon$ with $0<\epsilon \leq 2$, there exists $\delta>0$ such that the following implication holds for all $x, y \in X$ :

$$
\|x\| \leq 1, \quad\|y\| \leq 1 \quad \text { and } \quad\|x-y\| \geq \epsilon \quad \Longrightarrow \quad\left\|\frac{x+y}{2}\right\|<1-\delta .
$$

It is easy to see that a uniformly convex Banach space $X$ is strictly convex, but the converse is not true.

Definition 2.3 [41] Let $A$ and $B$ be nonempty subsets of a metric space $(X, d)$. The ordered pair $(A, B)$ is said to satisfy the property $U C$ if the following holds:

If $\left\{x_{n}\right\}$ and $\left\{z_{n}\right\}$ are sequences in $A$, and $\left\{y_{n}\right\}$ is a sequence in $B$ such that $d\left(x_{n}, y_{n}\right) \rightarrow$ $d(A, B)$ and $d\left(z_{n}, y_{n}\right) \rightarrow d(A, B)$, then $d\left(x_{n}, z_{n}\right) \rightarrow 0$.

Example 2.4 [41] The following are examples of a pair of nonempty subsets $(A, B)$ satisfying the property UC.

(i) Every pair of nonempty subsets $A, B$ of a metric space $(X, d)$ such that $d(A, B)=0$.

(ii) Every pair of nonempty subsets $A, B$ of a uniformly convex Banach space $X$ such that $A$ is convex.

(iii) Every pair of nonempty subsets $A, B$ of a strictly convex Banach space, where $A$ is convex and relatively compact and the closure of $B$ is weakly compact.

Definition 2.5 [40] Let $A$ and $B$ be nonempty subsets of a metric space $(X, d)$. The ordered pair $(A, B)$ satisfies the property $U C^{*}$ if $(A, B)$ has property $\mathrm{UC}$, and the following condition holds:

If $\left\{x_{n}\right\}$ and $\left\{z_{n}\right\}$ are sequences in $A$, and $\left\{y_{n}\right\}$ is a sequence in $B$ satisfying

(i) $d\left(z_{n}, y_{n}\right) \rightarrow d(A, B)$.

(ii) For every $\epsilon>0$, there exists $N \in \mathbb{N}$ such that

$$
d\left(x_{m}, y_{n}\right) \leq d(A, B)+\epsilon
$$

for all $m>n \geq N$,

then $d\left(x_{n}, z_{n}\right) \rightarrow 0$. 
Example 2.6 The following are examples of a pair of nonempty subsets $(A, B)$ satisfying the property UC*.

(i) Every pair of nonempty subsets $A, B$ of a metric space $(X, d)$ such that $d(A, B)=0$.

(ii) Every pair of nonempty closed subsets $A, B$ of uniformly convex Banach space $X$ such that $A$ is convex (see Lemma 3.7 in [42]).

\section{Best proximity point for multi-valued mapping theorems}

In this section, we investigate the existence and convergence of best proximity points for generalized multi-valued cyclic contraction pairs and obtain some new results on fixed point theorems for such mappings. We begin by introducing the notion of multi-valued cyclic contraction.

Definition 3.1 Let $A$ and $B$ be nonempty subsets of a metric space $X, T: A \rightarrow 2^{B}$ and $S$ : $B \rightarrow 2^{A}$. The ordered pair $(T, S)$ is said to be a generalized multi-valued cyclic contraction if there exists a function $\alpha:[d(A, B), \infty) \rightarrow[0,1)$ with

$$
\limsup _{x \rightarrow t^{+}} \alpha(x)<1
$$

for each $t \in[d(A, B), \infty)$ such that

$$
H(T x, S y) \leq \alpha(d(x, y)) d(x, y)+(1-\alpha(d(x, y))) d(A, B)
$$

for all $x \in A$ and $y \in B$.

Note that if $(T, S)$ is a generalized multi-valued cyclic contraction, then $(S, T)$ is also a generalized multi-valued cyclic contraction. Here, we state the main results of this paper on the existence of best proximity points for a generalized multi-valued cyclic contraction pair, which satisfies the property $\mathrm{UC}^{*}$ in metric spaces.

Theorem 3.2 Let $A$ and $B$ be nonempty closed subsets of a complete metric space $X$ such that $(A, B)$ and $(B, A)$ satisfy the property $U C^{*}$. Let $T: A \rightarrow C B(B)$ and $S: B \rightarrow C B(A)$. If $(T, S)$ is a generalized multi-valued cyclic contraction pair, then $T$ has a best proximity point in $A$, or $S$ has a best proximity point in $B$.

Proof We consider two cases separately.

Case 1 . Suppose that $d(A, B)=0$. Define the function $\beta:[d(A, B), \infty) \rightarrow[0,1)$ by

$$
\beta(t)=\frac{\alpha(t)+1}{2}
$$

for $t \in[d(A, B), \infty)=[0, \infty)$. Then we obtain that

$$
\limsup _{s \rightarrow t^{+}} \beta(s)<1
$$

for all $t \in[0, \infty)$.

Now, we will construct the sequence $\left\{x_{n}\right\}$ in $X$. Let $x_{0} \in A$ be an arbitrary point. Since $T x_{0} \in C B(B)$, we can choose $x_{1} \in T x_{0}$. If $x_{1}=x_{0}$, we have $x_{0} \in T x_{0}$, and then $x_{0}$ is a best 
proximity point of $T$. Also, it follows from (3.1) with $x=x_{0}$ and $y=x_{1}$ that $T x_{0}=S x_{1}$. This implies that $x_{1} \in S x_{1}$. Therefore, $x_{1}$ is a best proximity point of $S$, and we finish the proof. Otherwise, if $x_{0} \neq x_{1}$, by Lemma 1.1, there exists $x_{2} \in S x_{1}$ such that

$$
\begin{aligned}
d\left(x_{1}, x_{2}\right) \leq & H\left(T x_{0}, S x_{1}\right)+\left[\frac{1-\alpha\left(d\left(x_{0}, x_{1}\right)\right)}{2}\right] d\left(x_{0}, x_{1}\right) \\
\leq & \alpha\left(d\left(x_{0}, x_{1}\right)\right) d\left(x_{0}, x_{1}\right)+\left(1-\alpha\left(d\left(x_{0}, x_{1}\right)\right)\right) d(A, B) \\
& +\left[\frac{1-\alpha\left(d\left(x_{0}, x_{1}\right)\right)}{2}\right] d\left(x_{0}, x_{1}\right) \\
= & {\left[\frac{1+\alpha\left(d\left(x_{0}, x_{1}\right)\right)}{2}\right] d\left(x_{0}, x_{1}\right) } \\
= & \beta\left(d\left(x_{0}, x_{1}\right)\right) d\left(x_{0}, x_{1}\right) .
\end{aligned}
$$

If $x_{2}=x_{1}$, we have $x_{1} \in S x_{1}$, and then $x_{1}$ is a best proximity point of $S$. Also, it follows from (3.1) with $x=x_{2}$ and $y=x_{1}$ that $T x_{2}=S x_{1}$. This implies that $x_{2} \in T x_{2}$. Therefore, $x_{2}$ is a best proximity point of $T$, and we finish the proof. Otherwise, if $x_{2} \neq x_{1}$, by Lemma 1.1, there exists $x_{3} \in T x_{2}$ such that

$$
\begin{aligned}
d\left(x_{2}, x_{3}\right) \leq & H\left(S x_{1}, T x_{2}\right)+\left[\frac{1-\alpha\left(d\left(x_{1}, x_{2}\right)\right)}{2}\right] d\left(x_{1}, x_{2}\right) \\
= & H\left(T x_{2}, S x_{1}\right)+\left[\frac{1-\alpha\left(d\left(x_{2}, x_{1}\right)\right)}{2}\right] d\left(x_{2}, x_{1}\right) \\
\leq & \alpha\left(d\left(x_{2}, x_{1}\right)\right) d\left(x_{2}, x_{1}\right)+\left(1-\alpha\left(d\left(x_{2}, x_{1}\right)\right)\right) d(A, B) \\
& +\left[\frac{1-\alpha\left(d\left(x_{2}, x_{1}\right)\right)}{2}\right] d\left(x_{2}, x_{1}\right) \\
= & {\left[\frac{1+\alpha\left(d\left(x_{2}, x_{1}\right)\right)}{2}\right] d\left(x_{2}, x_{1}\right) } \\
= & \beta\left(d\left(x_{2}, x_{1}\right)\right) d\left(x_{2}, x_{1}\right) \\
= & \beta\left(d\left(x_{1}, x_{2}\right)\right) d\left(x_{1}, x_{2}\right) .
\end{aligned}
$$

By repeating this process, we can find $x_{n}$ such that

$$
d\left(x_{n+1}, x_{n+2}\right) \leq \beta\left(d\left(x_{n}, x_{n+1}\right)\right) d\left(x_{n}, x_{n+1}\right)<d\left(x_{n}, x_{n+1}\right)
$$

for all $n \in \mathbb{N}$.

Thus, for fixed $x_{0} \in A$, we can define a sequence $\left\{x_{n}\right\}$ in $X$ satisfying

$$
x_{2 n} \in S x_{2 n-1} \subseteq A \text { and } \quad x_{2 n-1} \in T x_{2 n-2} \subseteq B
$$

such that

$$
d\left(x_{n+1}, x_{n+2}\right) \leq \beta\left(d\left(x_{n}, x_{n+1}\right)\right) d\left(x_{n}, x_{n+1}\right)<d\left(x_{n}, x_{n+1}\right)
$$

for $n \in \mathbb{N}$. Therefore, $\left\{d\left(x_{n}, x_{n+1}\right)\right\}$ is a strictly decreasing sequence in $\mathbb{R}_{+}$. So $\left\{d\left(x_{n}, x_{n+1}\right)\right\}$ converges to some nonnegative real number $\rho$. Since $\limsup _{s \rightarrow \rho^{+}} \beta(s)<1$ and $\beta(\rho)<1$, 
there exist $r \in[0,1)$ and $\eta>0$ such that $\beta(s) \leq r$ for all $s \in[\rho, \rho+\eta]$. We can take $v \in \mathbb{N}$ such that

$$
\rho \leq d\left(x_{n}, x_{n+1}\right) \leq \rho+\eta
$$

for all $n \in \mathbb{N}$ with $n \geq v$. Then since

$$
d\left(x_{n+1}, x_{n+2}\right) \leq \beta\left(d\left(x_{n}, x_{n+1}\right)\right) d\left(x_{n}, x_{n+1}\right) \leq r d\left(x_{n}, x_{n+1}\right)
$$

for $n \in \mathbb{N}$ with $n \geq v$, we have

$$
\sum_{n=1}^{\infty} d\left(x_{n}, x_{n+1}\right) \leq \sum_{n=1}^{v} d\left(x_{n}, x_{n+1}\right)+\sum_{n=v}^{\infty} d\left(x_{n}, x_{n+1}\right)<\infty
$$

that is, $\left\{x_{n}\right\}$ is a Cauchy sequence. Since $X$ is complete, $\left\{x_{n}\right\}$ converges to some point $z \in X$. Clearly, the subsequences $\left\{x_{2 n}\right\}$ and $\left\{x_{2 n-1}\right\}$ converge to the same point $z$. Since $A$ and $B$ are closed, we derive that $z \in A \cap B$. We consider that

$$
\begin{aligned}
d(T z, z) & =\lim _{n \rightarrow \infty} d\left(T z, x_{2 n}\right) \\
& \leq \lim _{n \rightarrow \infty} H\left(T z, S x_{2 n-1}\right) \\
& \leq \lim _{n \rightarrow \infty} \beta\left(d\left(z, x_{2 n-1}\right)\right) d\left(z, x_{2 n-1}\right) \\
& \leq \lim _{n \rightarrow \infty} d\left(z, x_{2 n-1}\right) \\
& =0 \\
& =d(A, B) .
\end{aligned}
$$

Hence we get $d(z, T z)=d(A, B)$. Analogously, we also obtain $d(z, S z)=d(A, B)$.

Case 2. We will show that $T$ or $S$ have best proximity points in $A$ and $B$, respectively, under the assumption of $d(A, B)>0$. Suppose, to the contrary, that for all $a \in A, d(a, T a)>$ $d(A, B)$ and for all $b^{\prime} \in B, d\left(S b^{\prime}, b^{\prime}\right)>d(A, B)$.

Next, we define a function $\beta:[d(A, B), \infty) \rightarrow[0,1)$ by

$$
\beta(t)=\frac{\alpha(t)+1}{2}
$$

for all $t \in[d(A, B), \infty)$. So we derive $\limsup _{x \rightarrow t^{+}} \beta(x)<1$ and $\alpha(t)<\beta(t)$ for all $t \in$ $[d(A, B), \infty)$.

For each $a \in A$ and $b \in T a$, we have

$$
d(A, B)<d(a, T a) \leq d(a, b) .
$$

Therefore,

$$
[\beta(d(a, b))-\alpha(d(a, b))] d(A, B)<[\beta(d(a, b))-\alpha(d(a, b))] d(a, b),
$$


and then we get

$$
\begin{aligned}
& \alpha(d(a, b)) d(a, b)+(1-\alpha(d(a, b))) d(A, B) \\
& \quad<\beta(d(a, b)) d(a, b)+(1-\beta(d(a, b))) d(A, B) .
\end{aligned}
$$

Since $(T, S)$ is a generalized multi-valued cyclic contraction pair, by (3.2), we conclude

$$
\begin{aligned}
H(T a, S b) & \leq \alpha(d(a, b)) d(a, b)+(1-\alpha(d(a, b))) d(A, B) \\
& <\beta(d(a, b)) d(a, b)+(1-\beta(d(a, b))) d(A, B)
\end{aligned}
$$

for all $a \in A$ and $b \in T a$.

Similarly, we obtain that for each $b^{\prime} \in B$ and $a^{\prime} \in S b^{\prime}$, we have

$$
H\left(T a^{\prime}, S b^{\prime}\right)<\beta\left(d\left(a^{\prime}, b^{\prime}\right)\right) d\left(a^{\prime}, b^{\prime}\right)+\left(1-\beta\left(d\left(a^{\prime}, b^{\prime}\right)\right)\right) d(A, B) .
$$

Next, we will construct the sequence $\left\{x_{n}\right\}$ in $A \cup B$. Let $x_{0}$ be an arbitrary point in $A$ and $x_{1} \in T x_{0} \subseteq B$. From (3.3), there exists $x_{2} \in S x_{1} \subseteq A$ such that

$$
d\left(x_{1}, x_{2}\right)<\beta\left(d\left(x_{0}, x_{1}\right)\right) d\left(x_{0}, x_{1}\right)+\left(1-\beta\left(d\left(x_{0}, x_{1}\right)\right)\right) d(A, B) .
$$

Since $x_{1} \in B$ and $x_{2} \in S x_{1}$, from (3.4), we can find $x_{3} \in T x_{2}$ such that

$$
d\left(x_{2}, x_{3}\right)<\beta\left(d\left(x_{1}, x_{2}\right)\right) d\left(x_{1}, x_{2}\right)+\left(1-\beta\left(d\left(x_{1}, x_{2}\right)\right)\right) d(A, B) .
$$

Analogously, we can define the sequence $\left\{x_{n}\right\}$ in $A \cup B$ such that

$$
x_{2 n-1} \in T x_{2 n-2}, \quad x_{2 n} \in S x_{2 n-1}
$$

and

$$
d\left(x_{n}, x_{n+1}\right)<\beta\left(d\left(x_{n-1}, x_{n}\right)\right) d\left(x_{n-1}, x_{n}\right)+\left(1-\beta\left(d\left(x_{n-1}, x_{n}\right)\right)\right) d(A, B)
$$

for all $n \in \mathbb{N}$. Since $\beta\left(d\left(x_{n-1}, x_{n}\right)\right)<1$ and $d(A, B)<d\left(x_{n-1}, x_{n}\right)$ for all $n \in \mathbb{N}$, we get

$$
\begin{aligned}
d\left(x_{n}, x_{n+1}\right) & <\beta\left(d\left(x_{n-1}, x_{n}\right)\right) d\left(x_{n-1}, x_{n}\right)+\left(1-\beta\left(d\left(x_{n-1}, x_{n}\right)\right)\right) d\left(x_{n-1}, x_{n}\right) \\
& =d\left(x_{n-1}, x_{n}\right)
\end{aligned}
$$

for all $n \in \mathbb{N}$. Therefore, $\left\{d\left(x_{n-1}, x_{n}\right)\right\}$ is a strictly decreasing sequence in $\mathbb{R}_{+}$and bounded below. So the sequence $\left\{d\left(x_{n-1}, x_{n}\right)\right\}$ converges to some nonnegative real number $d$. Since limsup $\operatorname{sud}_{x \rightarrow d^{+}} \beta(x)<1$ and $\beta(d)<1$, there exist $d_{0} \in[0,1)$ and $\epsilon>0$ such that $\beta(s) \leq d_{0}$ for all $s \in[d, d+\epsilon]$. Now, we can take $N_{0} \in \mathbb{N}$ such that

$$
d \leq d\left(x_{n-1}, x_{n}\right) \leq d+\epsilon
$$


for all $n \geq N_{0}$. From (3.7), we have

$$
d\left(x_{n}, x_{n+1}\right)<d_{0} d\left(x_{n-1}, x_{n}\right)+\left(1-d_{0}\right) d(A, B)
$$

for all $n \geq N_{0}$. By the same consideration, we obtain

$$
d(A, B)<d\left(x_{n}, x_{n+1}\right)<d_{0}^{n-N_{0}} d\left(x_{N_{0}}, x_{N_{0}+1}\right)+\left(1-d_{0}^{n-N_{0}}\right) d(A, B)
$$

for all $n \geq N_{0}$. Since $d_{0} \in[0,1)$, we get

$$
\lim _{n \rightarrow \infty} d\left(x_{n}, x_{n+1}\right)=d(A, B)
$$

From (3.11), we conclude that

$$
\lim _{n \rightarrow \infty} d\left(x_{2 n}, x_{2 n+1}\right)=d(A, B)
$$

and

$$
\lim _{n \rightarrow \infty} d\left(x_{2 n+2}, x_{2 n+1}\right)=d(A, B)
$$

Since $\left\{x_{2 n}\right\}$ and $\left\{x_{2 n+2}\right\}$ are two sequences in $A$, and $\left\{x_{2 n+1}\right\}$ is sequence in $B$ with $(A, B)$ satisfies the property $\mathrm{UC}^{*}$, we derive that

$$
\lim _{n \rightarrow \infty} d\left(x_{2 n}, x_{2 n+2}\right)=0
$$

Since $(B, A)$ satisfies the property $\mathrm{UC}^{*}$, and by (3.11), we find that

$$
\lim _{n \rightarrow \infty} d\left(x_{2 n-1}, x_{2 n+1}\right)=0 .
$$

Next, we show that for each $\epsilon>0$, there exists $N \in \mathbb{N}$ such that for all $m>n \geq N$, we have

$$
d\left(x_{2 m}, x_{2 n+1}\right) \leq d(A, B)+\epsilon .
$$

Suppose, to the contrary, that there exists $\epsilon_{0}>0$ such that for each $k \geq 1$, there is $m_{k}>$ $n_{k} \geq k$ such that

$$
d\left(x_{2 m_{k}}, x_{2 n_{k}+1}\right)>d(A, B)+\epsilon_{0} .
$$

Further, corresponding to $n_{k}$, we can choose $m_{k}$ in such a way that it is the smallest integer with $m_{k}>n_{k} \geq k$ satisfying (3.17). Then we have

$$
d\left(x_{2 m_{k}}, x_{2 n_{k}+1}\right)>d(A, B)+\epsilon_{0}
$$

and

$$
d\left(x_{2\left(m_{k}-1\right)}, x_{2 n_{k}+1}\right) \leq d(A, B)+\epsilon_{0} .
$$


From (3.18), (3.19) and the triangle inequality, we have

$$
\begin{aligned}
d(A, B)+\epsilon_{0} & <d\left(x_{2 m_{k}}, x_{2 n_{k}+1}\right) \\
& \leq d\left(x_{2 m_{k}}, x_{2\left(m_{k}-1\right)}\right)+d\left(x_{2\left(m_{k}-1\right)}, x_{2 n_{k}+1}\right) \\
& \leq d\left(x_{2 m_{k}}, x_{2\left(m_{k}-1\right)}\right)+d(A, B)+\epsilon_{0} .
\end{aligned}
$$

Using the fact that $\lim _{k \rightarrow \infty} d\left(x_{2 m_{k}}, x_{2\left(m_{k}-1\right)}\right)=0$. Letting $k \rightarrow \infty$ in (3.20), we have

$$
\lim _{k \rightarrow \infty} d\left(x_{2 m_{k}}, x_{2 n_{k}+1}\right)=d(A, B)+\epsilon_{0}
$$

From (3.8), (3.9) and $(T, S)$ is a generalized multi-valued cyclic contraction pair, we get

$$
\begin{aligned}
d\left(x_{2 m_{k}}, x_{2 n_{k}+1}\right) \leq & d\left(x_{2 m_{k}}, x_{2 m_{k}+2}\right)+d\left(x_{2 m_{k}+2}, x_{2 n_{k}+3}\right)+d\left(x_{2 n_{k}+3}, x_{2 n_{k}+1}\right) \\
< & d\left(x_{2 m_{k}}, x_{2 m_{k}+2}\right)+d\left(x_{2 m_{k}+1}, x_{2 n_{k}+2}\right)+d\left(x_{2 n_{k}+3}, x_{2 n_{k}+1}\right) \\
\leq & d\left(x_{2 m_{k}}, x_{2 m_{k}+2}\right)+d\left(x_{2 n_{k}+3}, x_{2 n_{k}+1}\right)+\alpha\left(d\left(x_{2 m_{k}}, x_{2 n_{k}+1}\right)\right) d\left(x_{2 m_{k}}, x_{2 n_{k}+1}\right) \\
& +\left(1-\alpha\left(d\left(x_{2 m_{k}}, x_{2 n_{k}+1}\right)\right)\right) d(A, B) \\
< & d\left(x_{2 m_{k}}, x_{2 m_{k}+2}\right)+d\left(x_{2 n_{k}+2}, x_{2 n_{k}+1}\right)+\beta\left(d\left(x_{2 m_{k}}, x_{2 n_{k}+1}\right)\right) d\left(x_{2 m_{k}}, x_{2 n_{k}+1}\right) \\
& +\left(1-\beta\left(d\left(x_{2 m_{k}}, x_{2 n_{k}+1}\right)\right)\right) d(A, B) \\
\leq & d\left(x_{2 m_{k}}, x_{2 m_{k}+2}\right)+d\left(x_{2 n_{k}+2}, x_{2 n_{k}+1}\right)+d\left(x_{2 m_{k}}, x_{2 n_{k}+1}\right) \\
& +\left(1-d_{0}\right) d(A, B) .
\end{aligned}
$$

Letting $k \rightarrow \infty$ in (3.22) and using (3.14), (3.15) and (3.21), we have

$$
d(A, B)+\epsilon_{0} \leq d_{0}\left(d(A, B)+\epsilon_{0}\right)+\left(1-d_{0}\right) d(A, B)=d(A, B)+d_{0} \epsilon_{0}
$$

which is a contradiction. Therefore, (3.16) holds.

Since (3.12) and (3.16) hold, by using property $\mathrm{UC}^{*}$ of $(A, B)$, we have $d\left(x_{2 n}, x_{2 m}\right) \rightarrow 0$. Therefore, $\left\{x_{2 n}\right\}$ is a Cauchy sequence. By the completeness of $X$ and since $A$ is closed, we get

$$
\lim _{n \rightarrow \infty} x_{2 n}=p
$$

for some $p \in \bar{A}=A$. But

$$
\begin{aligned}
d(A, B) & \leq d\left(p, x_{2 n-1}\right) \\
& \leq d\left(p, x_{2 n}\right)+d\left(x_{2 n}, x_{2 n-1}\right)
\end{aligned}
$$

for all $n \in \mathbb{N}$. From (3.11) and (3.23),

$$
\lim _{n \rightarrow \infty} d\left(p, x_{2 n-1}\right)=d(A, B) .
$$


Since

$$
\begin{aligned}
d(A, B) & <d\left(x_{2 n}, T p\right) \\
& \leq H\left(S x_{2 n-1}, T p\right) \\
& =H\left(T p, S x_{2 n-1}\right) \\
& \leq \alpha\left(d\left(p, x_{2 n-1}\right)\right) d\left(p, x_{2 n-1}\right)+\left(1-d\left(p, x_{2 n-1}\right)\right) d(A, B) \\
& \leq d\left(p, x_{2 n-1}\right)
\end{aligned}
$$

for all $n \in \mathbb{N}$. By (3.23) and (3.24), we get

$$
d(p, T p)=d(A, B)
$$

In a similar mode, we can conclude that the sequence $\left\{x_{2 n-1}\right\}$ is a Cauchy sequence in $B$. Since $X$ is complete, and since $B$ is closed, we have

$$
\lim _{n \rightarrow \infty} x_{2 n-1}=q
$$

for some $q \in \bar{B}=B$. Since

$$
\begin{aligned}
d(A, B) & \leq d\left(x_{2 n}, q\right) \\
& \leq d\left(x_{2 n}, x_{2 n-1}\right)+d\left(x_{2 n-1}, q\right)
\end{aligned}
$$

for all $n \in \mathbb{N}$. It follows from (3.11) and (3.27) that

$$
\lim _{n \rightarrow \infty} d\left(x_{2 n}, q\right)=d(A, B) .
$$

Since

$$
\begin{aligned}
d(A, B) & <d\left(S q, x_{2 n+1}\right) \\
& \leq H\left(S q, T x_{2 n}\right) \\
& =H\left(T x_{2 n}, S q\right) \\
& \leq \alpha\left(d\left(x_{2 n}, q\right)\right) d\left(x_{2 n}, q\right)+\left(1-d\left(x_{2 n}, q\right)\right) d(A, B) \\
& \leq d\left(x_{2 n}, q\right)
\end{aligned}
$$

for all $n \in \mathbb{N}$, then by (3.27) and (3.28), we have

$$
d(q, S q)=d(A, B)
$$

From (3.26) and (3.30), we have a contradiction. Therefore, $T$ has a best proximity point in $A$ or $S$ has a best proximity point in $B$. This completes the proof.

Remark 3.3 If $d(A, B)=0$, then Theorem 3.2 yields existence of a fixed point in $A \cap B$ of two multi-valued non-self mappings $S$ and $T$. Moreover, if $A=B=X$ and $T=S$, then Theorem 3.2 reduces to Mizoguchi-Takahashi's fixed point theorem [17]. 
Note that every pair of nonempty closed subsets $A, B$ of a uniformly convex Banach space such that $A$ is convex satisfies the property $\mathrm{UC}^{*}$. Therefore, we obtain the following corollary.

Corollary 3.4 Let $A$ and $B$ be nonempty closed convex subsets of a uniformly convex $B a$ nach space $X, T: A \rightarrow C B(B)$ and $S: B \rightarrow C B(A)$. If $(T, S)$ is a generalized multi-valued cyclic contraction pair, then $T$ has a best proximity point in $A$ or $S$ has a best proximity point in $B$.

Next, we give some illustrative examples of Corollary 3.4.

Example 3.5 Consider the uniformly convex Banach space $X=\mathbb{R}$ with Euclidean norm. Let $A=[1,2]$ and $B=[-2,-1]$. Then $A$ and $B$ are nonempty closed and convex subsets of $X$ and $d(A, B)=2$. Since $A$ and $B$ are convex, we have $(A, B)$ and $(B, A)$ satisfy the property UC*

Let $T: A \rightarrow C B(B)$ and $S: B \rightarrow C B(A)$ be defined as

$$
T x=\left[\frac{-x-1}{2},-1\right]
$$

for all $x \in A$ and

$$
S y=\left[1, \frac{-y+1}{2}\right]
$$

for all $y \in B$.

Let $\alpha:[d(A, B), \infty) \rightarrow[0,1)$ be defined by $\alpha(t)=\frac{1}{2}$ for all $t \in[d(A, B), \infty)=[2, \infty)$. Next, we show that $(T, S)$ is a generalized multi-valued cyclic contraction pair with $\alpha(t)=\frac{1}{2}$ for all $t \in[2, \infty)$.

For each $x \in A$ and $y \in B$, we have

$$
\begin{aligned}
H(T x, S y) & =H\left(\left[\frac{-x-1}{2},-1\right],\left[1, \frac{-y+1}{2}\right]\right) \\
& \leq\left|\left(\frac{-x-1}{2}\right)-\left(\frac{-y+1}{2}\right)\right| \\
& =\left|\frac{-x+y-2}{2}\right| \\
& \leq \frac{1}{2}|x-y|+1 \\
& =\frac{1}{2} d(x, y)+\frac{1}{2} d(A, B) \\
& =\alpha(d(x, y)) d(x, y)+(1-\alpha(d(x, y))) d(A, B) .
\end{aligned}
$$

Therefore, all assumptions of Corollary 3.4 are satisfied, and then $T$ has a best proximity point in $A$, that is, a point $x=1$. Moreover, $S$ also has a best proximity point in $B$, that is, a point $y=-1$. 
Example 3.6 Consider the uniformly convex Banach space $X=\mathbb{R}^{2}$ with Euclidean norm.

Let

$$
A:=\{(0, x): x \geq 0\}
$$

and

$$
B=\{(2, y): y \geq 0\}
$$

Then $A$ and $B$ are nonempty closed and convex subsets of $X$ and $d(A, B)=2$. Since $A$ and $B$ are convex, we have $(A, B)$ and $(B, A)$ satisfy the property $\mathrm{UC}^{*}$.

Let $T: A \rightarrow C B(B)$ and $S: B \rightarrow C B(A)$ be defined as

$$
T(0, x)=\{2\} \times\left[0, \frac{x}{2}\right]
$$

and

$$
S(2, y)=\{0\} \times\left[0, \frac{y}{2}\right]
$$

for all $x, y \geq 0$.

Let $\alpha:[d(A, B), \infty) \rightarrow[0,1)$ define by $\alpha(t)=\frac{1}{2}$ for all $t \in[d(A, B), \infty)=[2, \infty)$. Next, we show that $(T, S)$ is a generalized multi-valued cyclic contraction pair with mapping $\alpha(t)=\frac{1}{2}$ for all $t \in[2, \infty)$.

For each $(0, x) \in A$ and $(2, y) \in B$, we have

$$
\begin{aligned}
H(T(0, x), S(2, y)) & =H\left(\{2\} \times\left[0, \frac{x}{2}\right],\{0\} \times\left[0, \frac{y}{2}\right]\right) \\
& =\sqrt{4+\left(\frac{|x-y|}{2}\right)^{2}} \\
& \leq \frac{1}{2}\left(\sqrt{4+|x-y|^{2}}\right)+1 \\
& =\frac{1}{2} d((0, x),(2, y))+\frac{1}{2} d(A, B) \\
& =\alpha(d((0, x),(2, y))) d((0, x),(2, y))+(1-\alpha(d((0, x),(2, y)))) d(A, B) .
\end{aligned}
$$

Therefore, all assumptions of Corollary 3.4 are satisfied, and then $T$ has a best proximity point in $A$ that is a point $(0,0)$. Furthermore, $S$ also has a best proximity point in $B$ that is a point $(2,0)$.

\section{Open problems}

- In Theorem 3.2, can we replace the property $\mathrm{UC}^{*}$ by a more general property?

- In Theorem 3.2, can we drop the property $\mathrm{UC}^{*}$ ?

- Can we extend the result in this paper to another spaces? 


\section{Competing interests}

The authors declare that they have no competing interests.

\section{Authors' contributions}

All authors contributed equally and significantly in writing this paper. All authors read and approved the final manuscript.

\section{Author details}

'Department of Mathematics, Faculty of Science, King Mongkut's University of Technology Thonburi (KMUTT), Bangkok, 10140, Thailand. ' Institut Supérieur d'Informatique et des Technologies de Communication de Hammam Sousse, Université de Sousse, Route GP1-4011, H. Sousse, Tunisie. ${ }^{3}$ Department of Mathematics, Atilim University, Incek, Ankara, 06836, Turkey. ${ }^{4}$ Department of Mathematics and Statistics, Faculty of Science and Technology, Thammasat University Rangsit Center, Pathumthani, 12121, Thailand.

\section{Acknowledgements}

Poom Kumam was supported by the Commission on Higher Education, the Thailand Research Fund and the King Mongkut's University of Technology Thonburi (Grant No. MRG5580213).

Received: 30 May 2013 Accepted: 26 September 2013 Published: 07 Nov 2013

\section{References}

1. Banach, S: Sur les opérations dans les ensembles abstraits et leurs applications aux équations intégrales. Fundam. Math. 3, 133-181 (1922)

2. Arvanitakis, AD: A proof of the generalized Banach contraction conjecture. Proc. Am. Math. Soc. 131(12), 3647-3656 (2003)

3. Boyd, DW, Wong, JSW: On nonlinear contractions. Proc. Am. Math. Soc. 20, $458-464$ (1969)

4. Merryfield, J, Rothschild, B, Stein, JD Jr:: An application of Ramsey's theorem to the Banach contraction principle. Proc. Am. Math. Soc. 130(4), 927-933 (2002)

5. Suzuki, T: A generalized Banach contraction principle that characterizes metric completeness. Proc. Am. Math. Soc. 136(5), 1861-1869 (2008)

6. Fan, K: Extensions of two fixed point theorems of FE Browder. Math. Z. 112, 234-240 (1969)

7. Di Bari, C, Suzuki, T, Vetro, C: Best proximity points for cyclic Meir-Keeler contractions. Nonlinear Anal. 69, 3790-3794 (2008)

8. Mongkolkeha, C, Kumam, P: Best proximity point theorems for generalized cyclic contractions in ordered metric spaces. J. Optim. Theory Appl. 155(1), 215-226 (2012)

9. Mongkolkeha, C, Cho, YJ, Kumam, P: Best proximity points for generalized proximal C-contraction mappings in metric spaces with partial orders. J. Inequal. Appl. 2013, 94 (2013)

10. Mongkolkeha, C, Cho, YJ, Kumam, P: Best proximity points for Geraghty's proximal contraction mapping mappings. Fixed Point Theory Appl. 2013, 180 (2013)

11. Nashine, HK, Vetro, C, Kumam, P: Best proximity point theorems for rational proximal contractions. Fixed Point Theory Appl. 2013, 95 (2013)

12. Sanhan, W, Mongkolkeha, C, Kumam, P: Generalized proximal $\psi$-contraction mappings and Best proximity points. Abstr. Appl. Anal. 2012, Article ID 896912 (2012)

13. Sintunavarat, W, Kumam, P: The existence theorems of an optimal approximate solution for generalized proximal contraction mappings. Abstr. Appl. Anal. 2013, Article ID 375604 (2013)

14. Vetro, C: Best proximity points: convergence and existence theorems for $p$-cyclic mappings. Nonlinear Anal. 73(7), 2283-2291 (2010)

15. Nadler, SB Jr: Multivalued contraction mappings. Pac. J. Math. 30, 475-488 (1969)

16. Daffer, PZ, Kaneko, H: Fixed points of generalized contractive multi-valued mappings. J. Math. Anal. Appl. 192 655-666 (1995)

17. Mizoguchi, N, Takahashi, W: Fixed point theorems for multi-valued mappings on complete metric space. J. Math. Anal. Appl. 141, 177-188 (1989)

18. Petrusel, A: On Frigon-Granas-type multifunctions. Nonlinear Anal. Forum 7, 113-121 (2002)

19. Reich, S: A fixed point theorem for locally contractive multi-valued functions. Rev. Roum. Math. Pures Appl. 17, 569-572 (1972)

20. Alesina, A, Massa, S, Roux, D: Punti uniti di multifunzioni con condizioni di tipo Boyd-Wong. Boll. Unione Mat. Ital. 4(8), 29-34 (1973)

21. Reich, S: Some problems and results in fixed point theory. Contemp. Math. 21, 179-187 (1983)

22. Daffer, PZ, Kaneko, H, Li, W: On a conjecture of S. Reich. Proc. Am. Math. Soc. 124, 3159-3162 (1996)

23. Jachymski, J: On Reich's question concerning fixed points of multimaps. Boll. Unione Mat. Ital. 7(9), 453-460 (1995)

24. Semenov, PV: Fixed points of multivalued contractions. Funct. Anal. Appl. 36, 159-161 (2002)

25. Eldred, AA, Anuradha, J, Veeramani, P: On equivalence of generalized multi-valued contractions and Nadler's fixed point theorem. J. Math. Anal. Appl. 336, 751-757 (2007)

26. Suzuki, T: Mizoguchi-Takahashi's fixed point theorem is a real generalization of Nadler's. J. Math. Anal. Appl. 340, 752-755 (2008)

27. Kirk, WA, Srinavasan, PS, Veeramani, P: Fixed points for mapping satisfying cyclical contractive conditions. Fixed Point Theory 4, 79-89 (2003)

28. Agarwal, RP, Alghamdi, MA, Shahzad, N: Fixed point theory for cyclic generalized contractions in partial metric spaces. Fixed Point Theory Appl. 2012, 40 (2012)

29. Eldered, AA, Veeramani, P: Convergence and existence for best proximity points. J. Math. Anal. Appl. 323, 1001-1006 (2006)

30. Eldered, AA, Veeramani, P: Proximal pointwise contraction. Topol. Appl. 156, 2942-2948 (2009)

31. Chen, CM: Fixed point theorems for cyclic Meir-Keeler type mappings in complete metric spaces. Fixed Point Theory Appl. 2012, 41 (2012) 
32. Karapinar, E: Fixed point theory for cyclic weak $\phi$-contraction. Appl. Math. Lett. 24, 822-825 (2011)

33. Karapinar, E, Sadarangani, K: Fixed point theory for cyclic $(\phi, \psi)$ contractions. Fixed Point Theory Appl. 2011, 69 (2011)

34. Karapinar, E, Erhan, IM, Ulus, AY: Fixed point theorem for cyclic maps on partial metric spaces. Appl. Math. Inform. Sci. 6, 239-244 (2012)

35. Karpagam, S, Agrawal, S: Best proximity points theorems for cyclic Meir-Keeler contraction maps. Nonlinear Anal. 74, 1040-1046 (2011)

36. Kosuru, GSR, Veeramani, P: Cyclic contractions and best proximity pair theorems (29 May 2011). arXiv:1012.1434v2 [math.FA]

37. Petruşel, G: Cyclic representations and periodic points. Stud. Univ. Babeş-Bolyai, Math. 50, 107-112 (2005)

38. Rezapour, S, Derafshpour, M, Shahzad, N: Best proximity point of cyclic $\varphi$-contractions in ordered metric spaces. Topol. Methods Nonlinear Anal. 37, 193-202 (2011)

39. Rus, IA: Cyclic representations and fixed points. Ann. "Tiberiu Popoviciu" Sem. Funct. Equ. Approx. Convexity 3, 171-178 (2005)

40. Sintunavarat, W, Kumam, P: Coupled best proximity point theorem in metric spaces. Fixed Point Theory Appl. 2012, $93(2012)$

41. Suzuki, T, Kikkawa, M, Vetro, C: The existence of best proximity points in metric spaces with the property UC. Nonlinear Anal., Theory Methods Appl. 71(7-8), 2918-2926 (2009)

42. Eldred, AA, Veeramani, P: Existence and convergence of best proximity points. J. Math. Anal. Appl. 323, $1001-1006$ (2006)

10.1186/1687-1812-2013-242

Cite this article as: Kumam et al.: Best proximity points and extension of Mizoguchi-Takahashi's fixed point

theorems. Fixed Point Theory and Applications 2013, 2013:242

\section{Submit your manuscript to a SpringerOpen ${ }^{\circ}$ journal and benefit from:}

- Convenient online submission

- Rigorous peer review

- Immediate publication on acceptance

- Open access: articles freely available online

- High visibility within the field

- Retaining the copyright to your article 